\title{
Environmental, Inhaled and Ingested Causes of Pulmonary Fibrosis
}

\author{
NAsreen Khalil, ${ }^{1}$ Andrew Churg, ${ }^{2}$ Nestor Muller, ${ }^{3}$ And Robert O’CONnOR ${ }^{2}$ \\ ${ }^{1}$ Department of Medicine, Respiratory Division, Vancouver General Hospital, V5Z 1M9, and The University of British Columbia, \\ V6T 1Z4, Canada \\ ${ }^{2}$ Department of Pathology, Vancouver General Hospital, V5Z 1M9, and The University of British Columbia, V6T 1Z4, Canada \\ ${ }^{3}$ Department of Radiology, Vancouver General Hospital, V5Z 1M9, and The University of British Columbia, V6T 1Z4, Canada
}

\begin{abstract}
Pulmonary fibrosis is a general term that refers to a collection of connective tissue around alveolar structures. There are over 200 disorders where the lungs may be involved in a fibrotic response. To determine the cause of pulmonary fibrosis requires an in depth understanding of the pathogenesis of pulmonary fibrosis and breadth of knowledge of the causative agents and associated disorders that may lead to pulmonary fibrosis. A comprehensive evaluation of the patient is absolutely essential, starting with detailed history that includes an occupational and environmental history because fibrogenic exposures can occur in many settings. Equally important is a history of ingestion of pharmaceutical or nonpharmaceutical substances. A physical examination and judicious investigations are always a part of any comprehensive clinical assessment but they are not commonly helpful in elucidating the cause of most pulmonary fibrotic disorders. Although, a chest film is invariably done, a logical and strongly recommended next step is a high-resolution computed tomography (HRCT). HRCT provides a better assessment of the radiological pattern, may suggest a diagnosis as well as direct the site, and type of lung biopsy. If the history and investigations do not lead to a diagnosis then a lung biopsy is required. Prevention or removal of the inciting agent is critical to the treatment of these disorders and in some instances corticosteroids may be of help.
\end{abstract}

Keywords. Pulmonary fibrosis; hypersensitivity pneumonitis; pneumoconiosis; berylliosis; silicosis; coal workers pneumoconiosis; asbestosis; drug-induced lung disease.

\section{INTRODUCTION}

There are numerous exogenous agents that can cause pulmonary fibrosis. These agents are encountered in a variety of environments that include occupational, recreational, and domestic sites (De Vuyst and Camus, 2000; American Thoracic Society, 2001; Green, 2002; Kim and Lynch, 2002; Glazer and Newman, 2004; Jacobs et al., 2005). The susceptibility of the host to respond by pulmonary fibrosis is likely to be complex and multifactorial. Similarly the pathogenesis is complex, may be specific to the inciting agent, and in most instances the pathogenesis is poorly understood (Nemery et al., 2001; Luster, 2002). This review cannot adequately address all aspects of the pathogenesis of the various disorders highlighted. However, the epidemiology, clinical recognition, radiological characterization, histological description and the natural course for a variety of pulmonary fibrotic diseases have been reported and these aspects will be emphasized. Although a plain radiograph is invariably done in nearly all cases, the high resolution computed axial tomography (HRCT) of the lung is a more sensitive investigative modality (Glazer et al., 2002; Kim and Lynch, 2002). For this reason the HRCT findings of the chest in each of the disorders will be discussed. Investigative studies such as pulmonary functions tests, blood work and treatment vary minimally amongst the various diseases, and these will be considered collectively in a separate section. Lastly, for the purposes of this review and based on currently clinically relevant exposures (Glazer and Newman, 2004), a selection from this vast number of dis-

Address correspondence to: Nasreen Khalil, Clinical Professor of Medicine, Respiratory Division, The University of British Columbia, Jack Bell Research Centre, 2660 Oak Street, Room 350, Vancouver, BC, V6H 3Z6; e-mail: nkhalil@interchange.ubc.ca orders will be reviewed consisting of hypersensitivity pneumonitis (HP) or extrinsic allergic alveolitis (EAA), selected pneumoconiosis, and drug induced pulmonary fibrosis. Other less common causes of pulmonary fibrosis are not reviewed.

\section{GENERAL COMMENTS ON EPIDEMIOLOGY}

The prevalence and incidence of pulmonary fibrosis caused by exogenous agents is essentially not available for a number of reasons. The reasons include the vast number of possible agents that potentially cause pulmonary fibrosis (Nemery et al., 2001; Jacobs et al., 2002, 2005; Attfield and Wood, 2004), the latency period from the time of exposure to the time of recognition, a lack of standardized diagnostic criteria, differences in the ability and/or vigilance of the physician to obtain a thorough exposure history, the lack of standardized means of characterizing and collecting data (Green, 2002). Nonetheless, some epidemiological data in the United States indicates the prevalence of occupational pulmonary fibrosis to be $14 \%$ while the incidence was reported as $12 \%$ (Coultas et al., 1994). The European Registry suggests a prevalence of 4-18\% of occupational pulmonary fibrosis and an incidence of 13-19\% (Thomeer et al., 2001).

\section{Hypersensitivity Pneumonitis}

Hypersensitivity pneumonitis (HP), also known as extrinsic allergic alveolitis (EAA), is due to an immunologically induced lymphocyte predominate inflammation in the peripheral airways and interstitium (Wild and Lopez, 2001; Yi et al., 2002; Lacasse et al., 2003; Mohr, 2004). HP is caused by repeated inhalation of a sensitizing agent (Wild and Lopez, 2001; Yi et al., 2002; Lacasse et al., 2003; Mohr, 2004). Although, there are many inciting agents that cause HP/EAA, the most common are inhaled organic substances and less commonly low molecular weight chemicals (Thomeer et al., 
TABLE 1.-Examples of agents that cause hypersensitivity pneumonitis.

\begin{tabular}{|c|c|c|}
\hline Microbial organisms/substance & Source & Name of disorder \\
\hline \multicolumn{3}{|l|}{ Thermophilic bacteria } \\
\hline Mycopolyspora faeni & Hay & Farmers lung \\
\hline Thermoactinomyces vulgaris & Mushroom compost & Mushroom worker's lung \\
\hline Thermoactinomyces candidus & Water reservoir in heater/humidifiers/air conditioner & Air conditioner/humidifier lung \\
\hline \multicolumn{3}{|l|}{ Nonthermophilic bacteria } \\
\hline Bacillus subtilis & Detergent & Detergent worker's lung \\
\hline Bacillus subtilis & Contaminated wood dust & Familial hypersensitivity pneumonitis \\
\hline Mycobacterium avium_-intracellulare & Water & Hot tub lung \\
\hline Aspergillus calvatus, & Moldy grain/barley & Malt-worker's lung \\
\hline Aspergillus sp & Moldy hay/ water & Farmers lung Air conditioner lung \\
\hline Penicillium casei & Cheese & Cheese maker's lung/Cheese washer's lung \\
\hline Penicillium roqueforti & Cheese & \\
\hline Penicillium frequentans & Moldy cork & Suberosis \\
\hline Penicillium chrysogenum & Moldy wood & Wood-worker's lung \\
\hline Aureobasidium pullans & Moldy sequoia & Sequoiosis \\
\hline Aureobasidium species & Water & Sauna lung \\
\hline Acanthamoeba castellani & Contaminated water & \\
\hline Mixture of amoeba, bacteria, and fungi & Water mists & $\begin{array}{l}\text { Office worker's lung, air conditioner lung, } \\
\text { ventilation pneumonitis }\end{array}$ \\
\hline Mixture of bacteria, fungi & Contaminated water & Machine operator's lung \\
\hline \multicolumn{3}{|l|}{ Animal proteins } \\
\hline \multirow[t]{2}{*}{ Avian (pigeon, dove, cockatiel, parakeet, turkey, duck) } & Bird excrement, blood, urine, feathers & $\begin{array}{l}\text { Bird fancier's lung, bird breeder's lung, pigeon } \\
\text { breeder's lung, cockatiel fancier's lung, } \\
\text { parakeet fancier's lung }\end{array}$ \\
\hline & Duck feathers & Duck fever \\
\hline Rat & Rat urine, serum, rodent dander & Rodent handler's lung, laboratory worker's lung \\
\hline Pork & Pituitary snuff & Pituitary snuff taker's lung \\
\hline Fish & Fish meal & Fish-meal worker's lung \\
\hline Silk worm & Silk worm larvae & Sericulturist lung \\
\hline Wheat weevil & Flour, infected wheat & Miler's lung \\
\hline Animal fur dust & Animal pelts & Furrier's lung \\
\hline \multicolumn{3}{|l|}{ Plants } \\
\hline
\end{tabular}

2001). In some instances ingested agents may result in a HPlike reaction (Ando et al., 1999; Patel et al., 2001; Camus et al., 2004a, 2004b) (Table 1). It is not uncommon for this type of lung reaction to be ascribed a name based on the source of exposure or the avocation in which the exposure occurred (Table 1). Despite the variety of agents that can cause HP, Thermophilic actinomycetes and avian antigens are responsible for most cases and the immunopathogenesis is common to all syndromes (Morris, 2003; Girard et al., 2004).

The pathogenesis of HP is complex but airborne particles that cause HP are less than $3 \mu \mathrm{m}$ in size, a size that easily reaches the lung parenchyma (Yi, 2002). Since a small proportion of exposed persons $(<10 \%)$ (Mohr, 2004) develop $\mathrm{HP}$, there may be genetic predisposition of the host in addition to environmental exposure (Ando et al., 1999; Patel et al., 2001; Girard et al., 2004; Mohr, 2004; Jacobs et al., 2005). The nature of the genetic predisposition is unclear, but MHC and TNF- $\alpha$ polymorphism is seen in HP patients compared to normal but exposed cohorts (Camarena et al., 2001; Schuyler, 2001). No single immunological mechanism can explain the features of HP (Aldo et al., 1999; Nemery et al., 2001; Patel et al., 2001; Wild and Lopez, 2001; Luster, 2002; Yi, 2002; Jacobs et al., 2005). However, there are 2 main mechanisms of pathogenesis suggested for HP, which are immune complex mediated response and T-cell mediated response (Ando et al., 1999). The observations that favor immunecomplex-induced disease is the occurrence of symptoms 4-5 hours after exposure, the presence of precipitating antibodies against the inciting antigen, and the detection of antigens, immunoglobulins, and complement components in the lungs of HP patients (Ando et al., 1999). It is speculated that the immune complex mediated response induces recruitment of activated neutrophils that may be important in the pathogenesis (Ando et al., 1999). Features that argue against an immune-complex mechanism are that precipitating antibodies do not correlate with disease activity but may represent exposure (Aberer et al., 2001; Yi, 2002; Selman, 200). In addition, the histology is not compatible with antigen-antibody complex-mediated disease (Lacasse et al., 2003; Mohr, 2004). 
There is more supportive evidence for T-cell mediated immune response in the pathogenesis of HP because there is: (1) Granulomatous inflammation in the lungs is histology typical of T cell-mediated tissue response (Ando et al., 1999). (2) Activated T-lymphocytes are found in the BAL and blood of HP patients (Ando et al., 2001); and (3) In animal models, adoptive transfer of the disease is seen with transfer of CD4+ cells but not CD8+ cells (Ando et al., 1999).

There is further evidence to support T-cell mediated pathogenesis. In patients with HP, the total number of leukocytes obtained by BAL is increased and the predominant cell type are T-Lymphocytes especially CD4+ cells. CD4+ cells that are present in the lungs and blood of patients with HP expand upon exposure to the causative antigen (Ando et al., 1999). Activated CD4+ cells generate IFN- $\gamma$ and IFN- $\gamma$ knockout mice do not develop significant numbers of granulomas upon stimulation suggesting that IFN- $\gamma$ is needed for the granulomatous response in HP (Gudmundsson and Hunninghake, 1997).

IL-12 is also released by CD4+ cells and is important in cell-mediated response. In HP CD8+ cells appear to be expanded but their role in the pathogenesis appears unclear (Ando et al., 1999). CD8+ cells produce similar cytokines but are induced by MHC class I molecules. For this reason $\mathrm{CD} 8+$ cells may have a role in hapten induced HP, which may be the mechanism of HP from exposure to chemicals such as isocyanate (Kalish and Askenase, 1999; Kang and Kim, 2006).

The role of macrophages in HP appears to be as antigen presenting cells. Also, alveolar macrophages in HP patient are activated to express a number of molecules that may be important in generating or sustaining the inflammatory response (Yi, 2002; Chen et al., 2005). For example, in HP AMs have increased amounts of ICAM, which may enhance the antigen-presenting capability of AMs and blockade of ICAM-1 interaction with its ligand reduces fibrosis in an experimental model of HP. The enhanced production of TNF- $\alpha$ by HP macrophages may be important in a number of functions including granuloma formation (Chen et al., 2004; Girard et al., 2004; Wallis et al., 2005).

The incidence and prevalence of HP is very difficult to determine especially in the population at large. However, in high-risk occupations, the prevalence of HP is between $5-15 \%$ exposed to a known antigen. For example, the prevalence of farmer's lung is 2-8\% of exposed individuals (Lopez and Salvaggio, 1987), while 6-21\% of pigeon breeders get HP and 15\% (Ohtani et al., 2003) of people exposed to humidification systems developed HP (Baur et al., 1992). In one instance up to $70 \%$ of individuals exposed to building with a contaminated ventilation system developed HP (Hodgson et al., 1987). There is no gender bias in HP, but since many labor-intensive duties in farms are male oriented, most patients with farmer's lung are male (Yi, 2002). HP is usually seen in the 4th to 6th decade, but cases of HP have been reported in children and even infants (Stauffer Ettlin et al., 2006). Curiously, a remarkably high percentage of patients with HP (80-95\%) (Yi, 2002; Stauffer Ettlin et al., 2006) are nonsmokers and it is speculated that smoking may lead to mild immunosuppression in the lungs, which may diminish the immunological response in the lung (Yi, 2002; Stauffer Ettlin et al., 2006). However, patients who have HP and smoke have a poorer 10-year survival (Navarro et al., 2006).

Histological changes in HP are variable and may be dependent on the length and extent of exposure. Acute HP may show interstitial inflammation with influx of leukocytes and neutrophils, which may be seen if the exposure was within 48 hours of the biopsy (Yi, 2002; Navarro et al., 2006). Bronchiolitis is also seen in early disease. In subacute HP there is interstitial inflammation with lymphocytes, plasma cells, mast cells, and macrophages (Figure 1A). There are poorly formed noncaseating granulomas and giant cells (Figure 1A). The granulomas may be seen throughout the interstitium, or within airspaces (Yi, 2002; Ohtani et al., 2005; Churg et al., 2006) and bronchiolitis may be present (Yi, 2002; Ohtani et al., 2005; Churg et al., 2006).

The classic histological triad of interstitial lymphocytic infiltration, bronchiolitis, and poorly formed granulomas is not always present (Herraez et al., 2002). However, other histological patterns such as bronchiolitis obliterans with organizing pneumonitis (BOOP) may be seen as many as $50 \%$ of HP/EA cases (Mohr, 2004; Ryu, 2006). When BOOP is

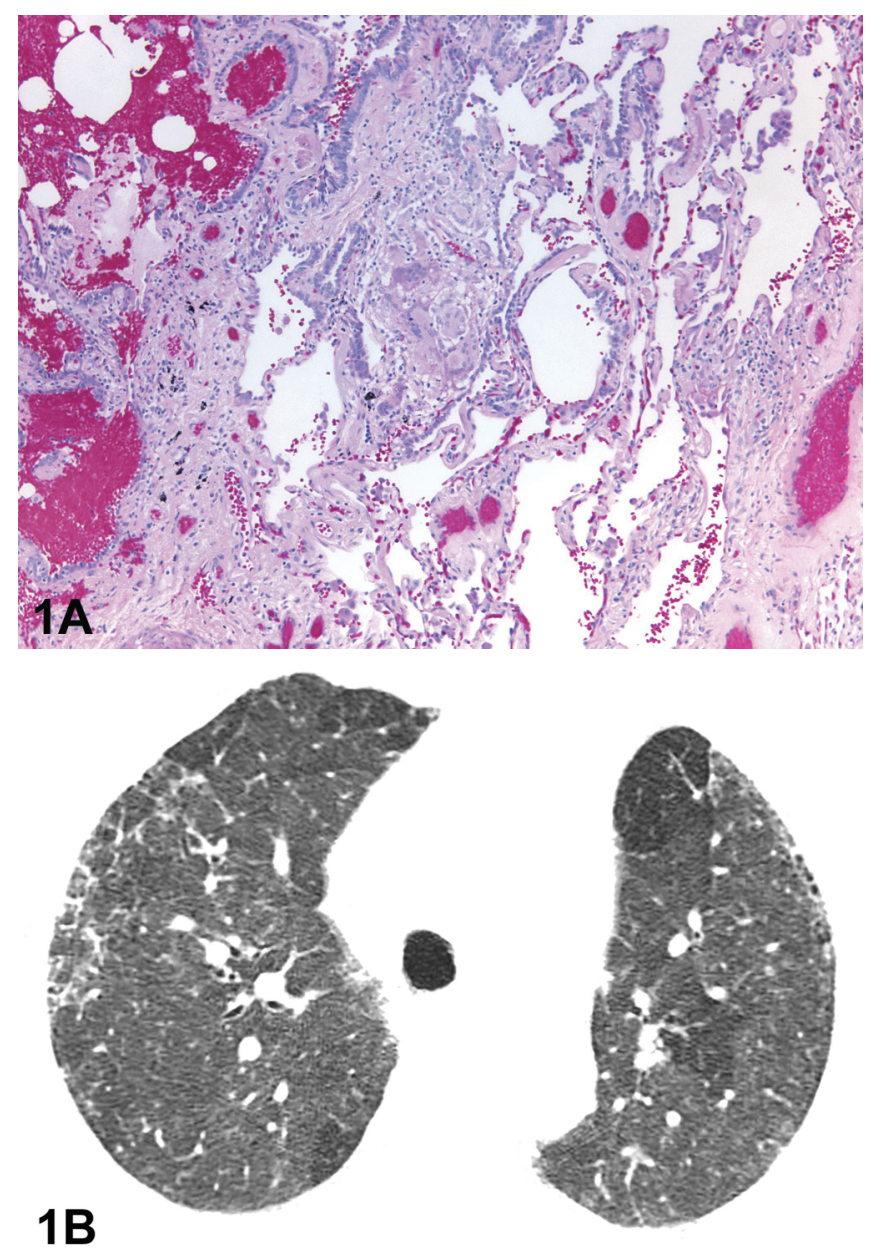

FIGURE 1.-(A) Histology of hypersensitivity pneumonitis. There is a loose granuloma (short arrow), interstitial fibrosis (long arrow), and interstitial inflammation $\left(^{*}\right)$. (B) HRCT of hypersensitivity pneumonitis. There is gas trapping (short arrow), fibrosis with nodularity (long arrow), and ground glass $\left(^{*}\right)$. 
seen it is usually in active cases of HP (Yi, 2002; Ross and Murray, 2004). Nonspecific interstitial pneumonia (NSIP), described later, may also be seen with HP (Katzenstein et al., 2002). These changes are neither pathognomonic nor specific for $\mathrm{HP}(\mathrm{Yi}, 2002)$.

In more chronic HP the granulomas may be better formed and resemble sarcoidosis. However, in chronic HP, there is an increase in a mononuclear cell infiltrate in the interstitium, as well as near granulomas, which can help distinguish HP from sarcoidosis (Kim and Lynch, 2002; Glazer and Newman, 2004). Chronic HP has more obvious fibrosis in the interstitium but there is also interstitial inflammation, which is predominantly lymphocytic with plasma cell. Other features of chronic HP are alveolar epithelial cell hyperplasia, thickened arterioles, and granulomas may be less easily identified. (Mohr, 2004; Ohtani et al., 2005; Churg et al., 2006). Also fibrosis may be seen in the peri-bronchiole areas and in some cases bronchiolitis obliterans may be present (Mohr, 2004; Ohtani et al., 2005; Churg et al., 2006; Ryu, 2006).

There are a variety of clinical presentations of HP that are not predictable for any particular clinical setting but it is conceivable to distinguish 3 presentations, which may overlap (Wild and Lopez, 2001; Yi, 2002; Lacasse et al., 2003; Mohr, 2004). Acute HP is the most common presentation (Wild and Lopez, 2001; Yi, 2002; Lacasse et al., 2003; Mohr, 2004) and symptoms usually occur $4-8$ hours after exposure with an acute onset of fever, possibly chills, dry cough, myalgias, and fatigue. The symptoms peak 12 to 24 hours after exposure and if there is no further exposure, the symptoms remit after 48 hours of (Wild and Lopez, 2001; Yi, 2002; Lacasse et al., 2003; Mohr, 2004) exposure. The symptoms recur upon subsequent exposure. On examination there may be slight fever and bibasilar crackles (Wild and Lopez, 2001; Yi, 2002; Lacasse et al., 2003; Mohr, 2004). Respiratory failure may occur requiring management in an ICU (Da Broi et al., 1999).

Subacute HP has a more insidious onset of cough, possible sputum production, and malaise, progressive shortness of breath especially with exertion (Wild and Lopez, 2001; Yi, 2002; Lacasse et al., 2003; Mohr, 2004). There may be anorexia and weight loss. The temporal association with exposure and symptoms is often not clear-cut. There is evidence of dyspnoea and bibasilar crackles (Wild and Lopez, 2001; Yi, 2002; Lacasse et al., 2003; Mohr, 2004).

Chronic HP is seen in approximately $5 \%$ of patients (Zacharisen et al., 2002; Mohr, 2004) and likely occurs with chronic low dose of exposure over a prolonged period of time. There may be no discernable history of acute or subacute symptoms (Yi, 2002; Zacharisen et al., 2002). The patient presents with progressive cough and/or shortness of breath and diminished exercise tolerance, anorexia, weight loss and rarely fever (Mohr, 2004). Clubbing may be present as well as inspiratory crackles and the clinical presentation may resemble idiopathic pulmonary fibrosis (Wild and Lopez, 2001).

The findings of HP on HRCT, are extensively described (Wild and Lopez, 2001; Kim and Lynch, 2002; Manning et al., 2002). In acute and subacute HP there is ground glass opacification, poorly defined centrilobular nodules, and areas of decreased attenuation that reflect gas trapping due to distal lumenal narrowing of bronchioles (Figure 1B). If there is no further exposure (Wild and Lopez, 2001; Kim and Lynch, 2002; Manning et al., 2002), the radiological changes may remit completely by 4-6 weeks (Wild and Lopez, 2001; Kim and Lynch, 2002; Manning et al., 2002). The extent of fibrosis, honeycombing, and traction bronchiectasis depends on the chronicity of HP. Chronic HP may resemble usual interstitial pneumonia (UIP) of IPF (discussed later) with subpleural and paraseptal fibrosis, honeycomb cysts and traction bronchiectasis. However, if micronodules or areas of gas trapping are present, then this is suggestive of chronic HP.

\section{Pneumoconioses}

Pneumoconioses are lung disorders caused by inhalation of mineral dusts (De Vuyst and Camus, 2000; Attfield and Wood, 2004) leading to pulmonary fibrosis and other changes located in the lung parenchyma (De Vuyst and Camus, 2000; Attfield and Wood, 2004). Known pneumoconioses are coal worker's pneumoconiosis (CWP), silicosis, asbestosis, hard metal lung disease, mixed dust pneumoconiosis, graphitosis, berylliosis, and talcosis (De Vuyst and Camus, 2000; Manning et al., 2002; Attfield and Wood, 2004). The more common pneumoconioses such as CWP, silicosis, asbestosis, hard metal lung and berylliosis will be reviewed (De Vuyst and Camus, 2000; Attfield and Wood, 2004). There is a decline in deaths attributed to CWP, silicosis and other pneumoconiosis. The decline is due to improved industrial hygiene and less dependence on mined substances (De Vuyst and Camus, 2000; Attfield and Wood, 2004). However, there is increased mortality from asbestosis. This is because mortality from asbestosis occurs $40-50$ years after exposure due to a long latency period (Attfield and Wood, 2004). Furthermore, asbestos-containing materials are still present in the workplace and will continue to contribute to the disease and rates of death (Attfield and Wood, 2004; Table 2).

\section{Asbestosis}

Asbestos is a fibrous mineral composed of silica used as an insulating material in hundreds of products (Mongan et al., 2000; Table 2). There are two types of asbestos fibers called serpentine and amphiboles asbestos. There are several asbestos related diseases such as asbestosis, which is pulmonary fibrosis, pleural plaques, a benign pleural reaction, bronchogenic carcinoma, and mesothelioma, a malignancy of the pleura (Mongan et al., 2000) but in this review only pulmonary fibrosis is discussed.

The pathogenesis of the fibrogenic nature of asbestos is due to a number of chemical and physical characteristics of the fiber. The asbestos fiber induces the release of TNF- $\alpha$, a fibrogenic cytokine (Mongan et al., 2000; Lee et al., 2006). In addition asbestos fibers also induce: reactive oxygen intermediates (ROI), which are capable of lung injury (Mongan et al., 2000); NF-kB, a transcription factor that regulates fibrogenic cytokines (NIH, 1978); and TGF- $\beta$ and TGF- $\alpha$,

TABLE 2.-Examples of sources of asbestos.

\begin{tabular}{ll}
\hline \hline Industrial & \multicolumn{1}{c}{ Mining } \\
\hline & Handling, production of asbestos, shipbuilding \\
Small businesses & Electricians, plumbers, insulators, demolition workers \\
New sources & Soil \\
& Dental material \\
\hline
\end{tabular}



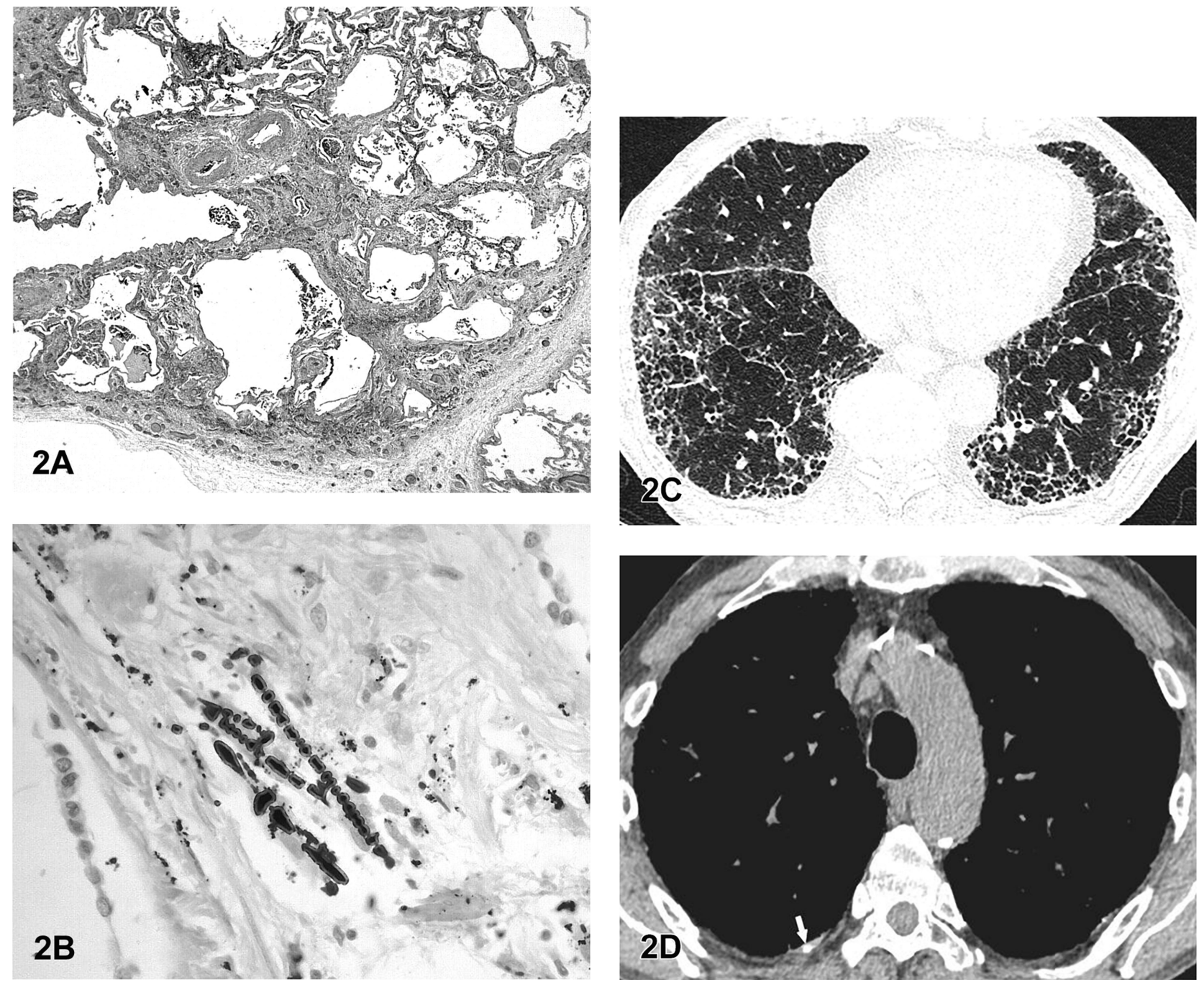

FIGURE 2.-Asbestosis: (A) Low-power view showing a pattern of diffuse interstitial fibrosis. (B) Iron stain showing several asbestos bodies. The combination of diffuse fibrosis and asbestos bodies is required for the pathologic diagnosis of asbestosis. (C) HRCT shows pulmonary fibrosis in the subpleural regions with traction bronchiectasis and honeycombing. (D) Calcified pleural plaque is also seen (white arrow).

which are both fibrogenic cytokines (NIH, 1978). In addition asbestos induces phosphorylation of MAPKs at sites of fibrosis, suggesting a role in the pathogenesis of fibrosis by prolifertion of fibroblasts (Mongan et al., 2000; Chong et al., 2006).

Histology of asbestosis demonstrates pulmonary fibrosis with honeycombing, fibroblast foci in the interstitium and respiratory bronchioles and asbestos bodies (Rimal et al., 2005) (Figure 2A). Asbestos bodies are asbestos fibers coated with iron and protein and the presence of asbestos bodies strongly testifies to the etiology of the pulmonary fibrosis (Mongan et al., 2000; Rimal et al., 2005) (Figure 2B). Most patients with asbestosis present many years after exposure with slowly progressive cough and dyspnoea (Mongan et al., 2000; Attfield and Wood, 2004), and on auscultation there are inspiratory crackles. Clubbing is occasionally seen (Mongan et al., 2000).

There are a number of radiological changes seen with asbestos exposure and depend on the latency period from the time of exposure (Ross and Murray, 2004). Pulmonary fibrosis occurs after relatively high levels of exposure having occurred for an extended period of time (Ross and Murray, 2004) and is usually seen approximately 20 years after exposure (Ross and Murray, 2004). Typically in early disease, there are peripheral reticular lesions, interlobular septal thickening, and intralobular scarring occurring in the posterior and basal regions (Ross and Murray, 2004). There are reticular infiltrates especially in the lower lobes (Ross and Murray, 2004; Arakawa et al., 2005). With advancing disease there is increased fibrosis, honeycombing, and traction bronchiectasis (Figure 2C). These lesions resemble the radiological changes seen in another fibrotic lung disease, idiopathic pulmonary fibrosis (IPF) (Figure 2C). In 10\% of cases pleural plaques are present and help distinguish asbestosis from IPF (54) (Figure $2 \mathrm{D})$. The clinical diagnosis is made on demonstrating pulmonary fibrosis and evidence of exposure to asbestos such as pleural plaques or asbestos bodies in bronchoalveolar lavage (BAL) or lung tissue (Ohtani et al., 2003). 
TABLE 3.-Diseases caused by silica.

\begin{tabular}{l}
\hline \hline Acute silicosis \\
Accelerated silicosis \\
Simple silicosis \\
Pulmonary tuberculosis \\
Interstitial fibrosis \\
Bronchitis \\
Emphysema \\
Extrapulmonary (rheumatological, vascular disease, glomerulonephritis)
\end{tabular}

\section{Silicosis}

Traditionally, silicosis as an inhaled fibrotic lung disease was encountered primarily in miners. The incidence of silicosis is decreasing due to better industrial hygiene measures in mining (De Vuyst and Camus, 2000). Despite these efforts silicosis is still seen because silicosis may occur with sand blasting, processing of scouring powders, silica flour or use of diatomaceous earth (De Vuyst and Camus, 2000; Flynn and Susi, 2003). Silicosis may also occur in dental technicians, who use grinding material with silica (De Vuyst and Camus, 2000). Farmers can get silicosis by plowing agricultural soils that may contain silica or use of organic fertilizers containing silica (De Vuyst and Camus, 2000).

Silicosis occurs by inhalation of crystalline silica as quartz, cristobalite, or trydimite (De Vuyst and Camus, 2000) found in sand blasting, drilling, pulverizing, cutting bricks and concrete blocks, grinding concrete, and other pneumatic equipment (Flynn and Susi, 2003). Exposure to silica results in a number of disease (Table 3), but of these conditions, chronic silicosis is a fibrotic lung disease. Chronic silicosis is the most common disease caused by silica exposure and occurs after approximately 10 years of exposure with dust content of $18-30 \%$ of crystalline silica (Flynn and Susi, 2003).

The pathogenesis of silicosis may predominantly be regulated by generation of ROI. Freshly fractured silica results in generation of ROI such as $\cdot \mathrm{OH}, \mathrm{H}_{2} \mathrm{O}_{2}$, and $\mathrm{O}_{2}^{--}$that can lead to lung injury by peroxidation (Flynn and Susi, 2003). The ROI can induce NF- $\kappa \mathrm{B}$, a transcription factor whose gene products are inflammatory and fibrotic in nature (Flynn and Susi, 2003). In particular NF- $\kappa$ B induces TNF- $\alpha$ production and release (Flynn and Susi, 2003), which appears to be important in the fibrosis and nodular lesions seen in silicosis (Flynn and Susi, 2003). Silica particles can also activate phosphorylation of MAPKs, important in proliferation of a number of cells including fibroblasts (Khalil et al., 2005). In addition metal iron present on silica can also lead to generation of $\mathrm{OH}^{-}$and $\cdot \mathrm{OH}$ resulting in lung injury and fibrosis (Flynn and Susi, 2003). Another silica associated group, the $\mathrm{SiOH}$ has been shown to induce $\mathrm{OH}, \mathrm{H}_{2} \mathrm{O}_{2}$, and $\mathrm{NF}-\kappa \mathrm{B}$, which may be involved in lung injury, fibrosis and nodule formations (Flynn and Susi, 2003).

Histology of silicosis shows pulmonary fibrosis but the most distinctive lesion of silicosis is the silicotic nodule, which is usually found in the respiratory bronchiole (Figure 3). The nodules may measure 4 to $10 \mathrm{mms}$ and enlarge further with continued exposure (Flynn and Susi, 2003). A silicotic nodule has concentric fibrotic hyalinized laminar layers of collagen, fibroblasts, and lymphocytes (Rimal et al., 2005) and dust (Flynn and Susi, 2003). The dust may be in macrophages in the center of the nodule and be refractile

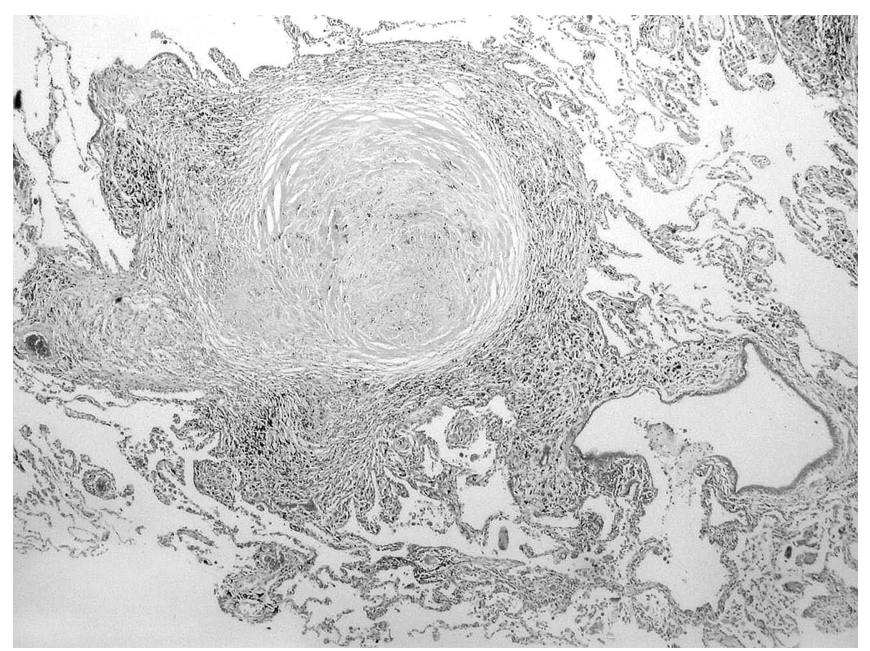

FIGURE 3.-Simple silicosis: A silicotic nodule with a whorled collagenous center is present; around the periphery of the nodule are pigmented dust-bearing macrophages.

in polarized light (Arakawa et al., 2005). Perinodular emphysema may be present, which can rupture giving rise to pneumothorax (Arakawa et al., 2005).

With continued exposure the small nodules of simple silicosis enlarge, coalesce and result in progressive massive fibrosis or conglomerate fibrosis. The nodules in these instances are greater than $1 \mathrm{~cm}$. Silicosis is predominant in the upper lobes and pleural involvement with thickening may be present. The nodules can cavitate and concomitant mycobacterial disease may occur (Flynn and Susi, 2003).

Clinical presentation of silicosis is characterized by no symptoms in mild disease but as the disease progresses, there is increased shortness of breath (Flynn and Susi, 2003; Scabilloni et al., 2005). Progression of symptoms and the severity of disease may occur even after termination of exposure exposure (Flynn and Susi, 2003; Scabilloni et al., 2005). Physical examination is not very specific, but inspiratory crackles are heard and clubbing is uncommon (Flynn and Susi, 2003; Scabilloni et al., 2005). When progression of disease is extensive the symptoms of dyspnoea are severe (Flynn and Susi, 2003; Scabilloni et al., 2005).

HRCT of the chest show multiple nodularties that are uniform in size with predominance in the upper lobes and in a posterior location (Flynn and Susi, 2003; Scabilloni et al., 2005). Calcification of nodules is seen in $10-20 \%$ of cases. Hilar and mediastinal lymph nodes may be enlarged and calcify in an eggshell pattern (Ross and Murray, 2004).

\section{Beryllium}

Beryllium is a hard, low-density metal and is naturally found in mineral rocks, coal, soil, and volcanic dust. Beryllium has a number of industrial uses (Table 4). Berylliosis is seen in not only workers exposed to beryllium, but in the people living in neighborhoods with beryllium manufacturing industries (Ross and Murray, 2004). Any occupation that leads to aerosolized beryllium can lead to sensitization and berylliosis (Ross and Murray, 2004).

The pathogenesis of berylliosis is speculated to be a hypersensitivity response. The response is mediated by MHC II 
TABLE 4.- Sources of beryllium.

\begin{tabular}{l}
\hline \hline Nuclear weapons \\
Aerospace industry \\
Automotive \\
Computer \\
Electronics \\
Dental supplies \\
Nuclear reactors \\
Smelters \\
Telecommunications \\
\hline
\end{tabular}

complex, cell-mediated immune response with T-helper cell generation of IFN- $\gamma$ and TNF- $\alpha$ (Ross and Murray, 2004). Beryllium induces an abnormal response in lymphocyte proliferation. Ex-vivo cultures of T lymphocytes incubated with beryllium leads to lymphocyte proliferation. The lymphocyte proliferation test identifies hypersensitivity in exposed persons who may develop chronic beryllium disease (Ross and Murray, 2004). Histologically there are noncaseating granulomas along the bronchovasular bundle in the bronchial submucosa and in the interstitium (Figure 4). There is a mononuclear cell infiltrate in the interstitium (Ross and Murray, 2004).

Interstitial fibrosis occurs variably and depends on the chronicity of the exposure (Ross and Murray, 2004). Clinically up to $10 \%$ of persons sensitized to beryllium will progress to berylliosis (Ross and Murray, 2004). Many exposed patients with abnormal radiology may be asymptomatic (Ross and Murray, 2004). When symptoms occur, they may be insidious in onset with cough, dyspnoea, fatigue, and malaise. On HRCT there are parenchymal nodules, small peribronchiole and subpleural nodules, ground glass infiltration, periseptal thickening and fibrosis. In chronic disease, subpleural cysts may occur (Ross and Murray, 2004). The radiological changes are similar to sarcoidosis. In more chronic disease there may be fibrosis and enlargement of hilar lymph nodes seen in up to $45 \%$ of patients. Pleural thickening is also seen (Ross and Murray, 2004; Chong et al., 2006).

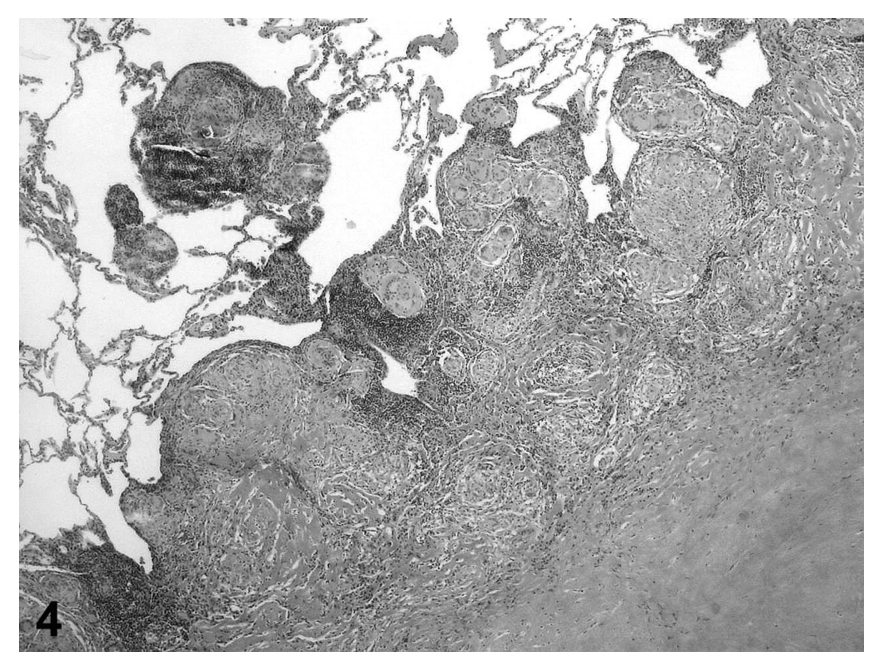

FIGURE 4.-Berylliosis: Edge of a nodular lesion with peripheral granulomas and central fibrosis. An isolated granuloma is also present slightly away from the large nodule.

\section{Coal Worker's Pneumoconiosis}

Coal worker's pneumoconiosis (CWP), was a relatively common occupational lung disease at one time until the mining of coal decreased (Nemery et al., 2001). CWP can be divided into simple pneumoconiosis characterized by minor fibrosis or progressive massive fibrosis (PMF) characterized by extensive fibrotic lesions in the lungs (Nemery et al., 2001). The prevalence of CWP has declined because of decrease in coal mining and better industrial hygiene measures (Ding et al., 2002). CWP may still be seen because of additional sources of exposure such as milling for graphite (Ding et al., 2002).

The pathogenesis of CWP is mediated by alveolar macrophages activated by coal dust particles to release TNF$\alpha$ and IL-6, PDGF IGF-1, TGF- $\beta$ (Nemery et al., 2001). TGF- $\beta$, PDGF and IGF- 1 are found in increased quantities in the BAL fluid of patients with CWP compared to controls (Nemery et al., 2001). The occurrence of disease depends on the quality of coal and carbon content. If there is increased surface area or silica content on the coal dust then the occurrence of disease is more likely (Nemery et al., 2001; Ding et al., 2002). The severity, which is reflected by PMF, is dependent on severity of exposure and proportion of silica in the dust (Ding et al., 2002). Since silica may be mixed with coal, it may be difficult to distinguish between CWP and silicosis (Ross and Murray, 2004).

CWP usually has minimal symptoms of cough and dyspnoea but may present with chronic bronchitis-like symptoms with cough and sputum production reflecting coal-induced irritation of the airways (Flynn and Susi, 2003). However, when pulmonary fibrosis ensues, there is increased dyspnoea and decreased exercise tolerance (Ding et al., 2002). Histologically carbon particles are seen in respiratory bronchioles with adjacent fibrosis (Ross and Murray, 2004) and focal emphysema (Ross and Murray, 2004). PMF can resemble the lesions seen in silicosis. However, more characteristic of PMF is haphazardly arranged collagen with pigment-laden macrophages, free pigment, and there may be necrosis of tissue (Nemery et al., 2001). When PMF is present, it is associated with severe symptoms and hypoxemia (Ross and Murray, 2004).

In simple CWP HRCT shows multiple small round nodules, with occasional reticulation, which are smaller than those seen in silicosis (Ross and Murray, 2004). When calcification occurs it is usually central in location of the nodule (Nemery et al., 2001). While in silicosis the calcification is more diffusely distributed in the nodule (Nemery et al., 2001). In PMF the HRCT shows large opacifications and PMF has to be distinguished from cancer (Nemery et al., 2001). Positron emission tomography (PET) is helpful in making this distinction (Nemery et al., 2001).

\section{Hard Metal Lung Disease}

Hard metal lung disease is another form of dust exposure that leads to pulmonary fibrosis (Vanhee et al., 1995). Hard metal lung disease has previously been referred to as hard metal pneumoconiosis, hard metal lung disease, cobalt lung, or giant cell interstitial pneumonitis (Vanhee et al., 1995). Hard metal is a man-made substance composed of tungsten carbide and cobalt (Vanhee et al., 1995). It is not necessarily 
a pneumoconioses because the occurrence is not dose dependent but the disease occurs due to specific host susceptibility (Vanhee et al., 1995).

Also the airways may also be involved in addition to the lung parenchyma (Vanhee et al., 1995). Some examples of occupations associated with hard metal disease are in mining and refining hard metal, manufacturing hard metal by mixing, compressing, drilling, coating surfaces, and diamond tooling (Vanhee et al., 1995). The mechanism of fibrosis is not clearly defined and has not been reproduced in animal models. It is speculated that the surface of tungsten carbide is an electron conductor and generates ROI, that may in turn lead to pulmonary fibrosis by a similar mechanism described for asbestosis and silicosis (Vanhee et al., 1995). The mechanism of individual susceptibility is not known but may be associated with HLA-DPB1 allele (Vanhee et al., 1995).

The histological changes are patchy in distribution and the most characteristic feature is multineucleated giant cell infiltration (Vanhee et al., 1995; Figure 5A). This finding is felt to be very specific to hard metal exposure. There is also infiltration of the interstitium with lymphocytes and plasma
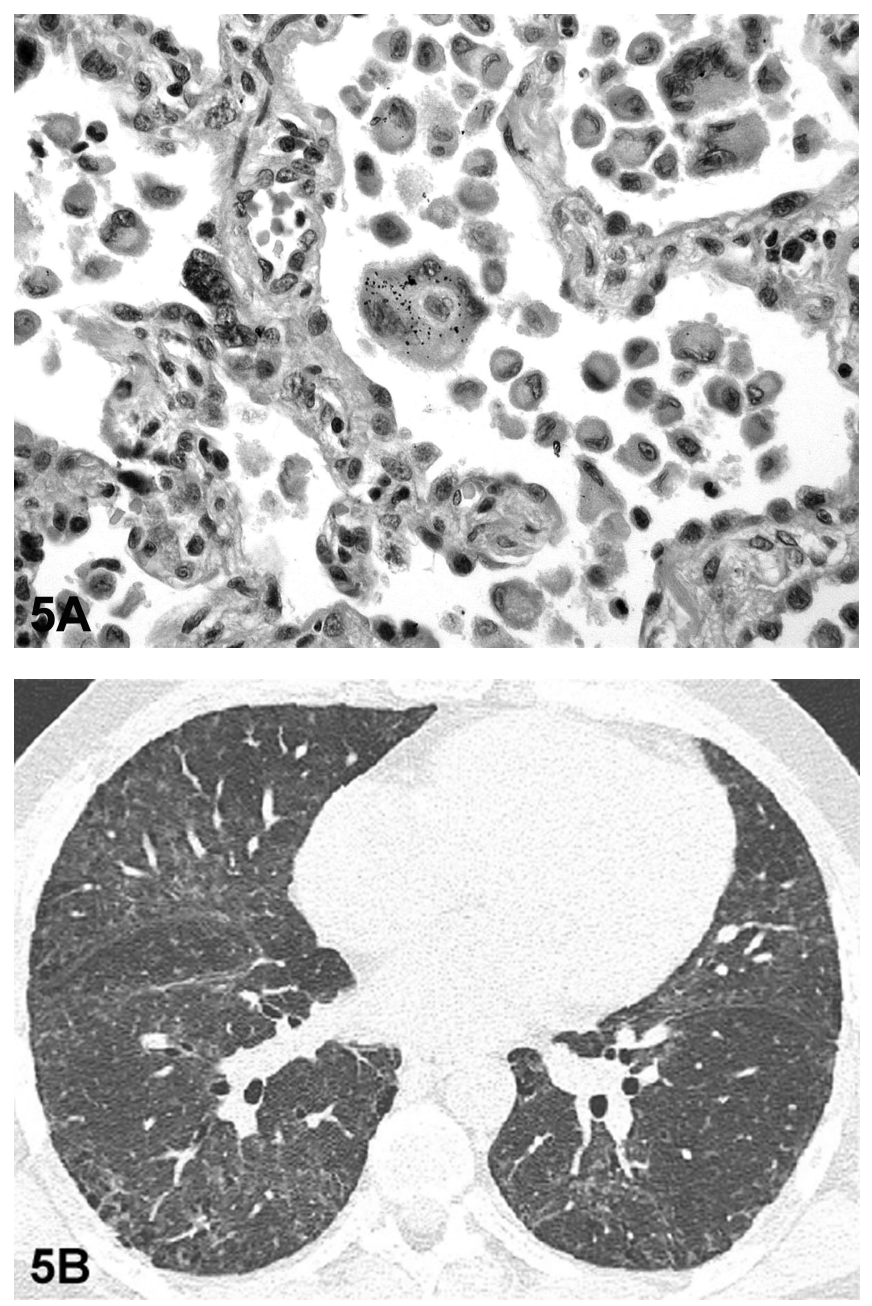

FIGURE 5.-Hard metal disease: (A) On histology an area of mild interstitial fibrosis with associated airspace macrophages and giant cells. (B) HRCT shows ground glass in a diffuse pattern. cells. Type 2 pneumocyte hyperplasia and alveolar infiltration of macrophages suggestive of a histology called desquamative interstitial pneumonia (DIP; reviewed later) may be seen. These lesions are often cetrilobular. A few granulomas may be present but the histology does not resemble HP because the granulomas are less in number and there is a propensity of giant cell infiltration in the interstitium. In some cases BOOP-like changes may be present. Mineral analysis of BAL or lung may demonstrate the presence of tungsten or cobalt (Vanhee et al., 1995).

Clinical presentation is variable from asymptomatic alveolitis to shortness of breath (Vanhee et al., 1995). Some patients have systemic symptoms such as fatigue, malaise, weight loss dermatitis, and pruritus. There may be acute respiratory symptoms of a cough and dyspnoea or more insidious progressive shortness of breath and exercise intolerance (Vanhee et al., 1995). Some individuals may have upper respiratory tract symptoms such as sneezing, coryza, cough, and nasal stuffiness (Vanhee et al., 1995). It is important to note that the length of exposure does not correlate with occurrence or severity of disease. Symptoms compatible with asthma or bronchitis may also be present (Vanhee et al., 1995). On examination there may be inspiratory crackles. HRCT is not specific and may have minor changes in comparing the symptoms. Minor linear opacities and ground glass may be seen especially in the lower lobes (Figure 5B).

\section{Drug-Induced Pulmonary Fibrosis}

Numerous drugs can cause infiltrative lung disease that can lead to pulmonary fibrosis (Camus et al., 2004; Table 5). Although the oral and intravenous routes are most commonly associated with pulmonary fibrosis, pulmonary fibrosis can occur with any route of drug delivery (Camus et al., 2004). Usually the pulmonary fibrosis happens as a spontaneous event (Camus et al., 2004). There are many interstitial patterns caused by drugs such as nonspecific interstitial pneumonia (NSIP), usual interstitial pneumonia (UIP), eosinophilic pneumonia, desquamative interstitial pneumonia (DIP), lymphoid interstitial pneumonia (LIP) and granulomatous reactions. NSIP, initially described by Katzenstein and Fiorelli, is characterized by uniform histological changes with infiltration of the interstitial inflammatory cells such as lymphocytes and plasma cells (Katzenstein and Fiorelli, 1994; American Thoracic Society, 2001; Martinez, 2006). There are no granulomas, and no temporal heterogeneity as seen in UIP (Katzenstein and Fiorelli, 1994; American Thoracic Society, 2001; Martinez, 2006).

There is variability in the extent of fibrosis that may be seen and if substantial fibrosis is present then the lesion

TABLE 5.- Some common drugs that cause pulmonary fibrosis.

\begin{tabular}{lc}
\hline \hline Chemotherapeutic agents & $\begin{array}{c}\text { Bleomycin, bisulfan, chlorambucil, } \\
\text { cyclophosphamide, methotrexate, } \\
\text { mitomycin, nitrosoureas, } \\
\text { docetaxel gemcitabine, irinotecan, } \\
\text { vinorelbine } \\
\text { Nitrofurantoin } \\
\text { Colony stimulating factor, } \\
\text { interferons, gefitinib, amiodarone }\end{array}$ \\
$\begin{array}{l}\text { Antibiotics } \\
\begin{array}{l}\text { Others (biological agents; } \\
\text { inflammation and diffuse alveolar } \\
\text { damage that can lead to pulmonary } \\
\text { fibrosis) }\end{array} \\
\text { Radiation }\end{array}$ & Confined to the field of irradiation \\
\hline
\end{tabular}


is often called fibrosing NSIP (FNSIP). Histology with minimal or no fibrosis is referred to as cellular NSIP (CNSIP) (Katzenstein and Fiorelli, 1994; American Thoracic Society, 2001; Martinez, 2006). The histology of UIP is that of temporal heterogeneity, with normal lung being interspersed with interstitial fibrosis, honeycomb cysts that are distorted air-spaces, and fibroblast foci, which are palisades of fibroblasts and connective tissue (Katzenstein and Fiorelli, 1994; American Thoracic Society, 2001; Martinez, 2006). DIP is histologically characterized by intra-alveolar macrophages, multinucleated giant cells, eosinophils, and lymphocytes (Davies et al., 2004).

Histologically, LIP is characterized by infiltrates with polymorphonuclear cells, primarily $\mathrm{T}$ lymphocytes, plasma cells, lymphoblasts, and histiocytes (Swigris et al., 2002). Polyclonal B lymphocytes are seen in peribronchial regions (Swigris et al., 2002). There is minor interstitial thickening and inflammation (Swigris et al., 2002). In eosinophilic pneumonia there is infiltration of the interstitium primarily with eosinophils as well as lymphocytes, plasma cells, polymorphonuclear cells (Tefferi et al., 2006). The more detailed histological characteristics of these terms are reviewed elsewhere (Katzenstein and Fiorelli, 1994; American Thoracic Society, 2001; Swigris et al., 2002; Davies et al., 2004; Martinez, 2006; Tefferi et al., 2006). However, of these interstitial patterns, reactions leading to pulmonary fibrosis are NSIP, UIP, and granulomatous reactions (Camus et al., 2004). It is of note that a single drug may give more than one pattern of lung involvement (Camus et al., 2004).

The prevalence of drug-induced pulmonary fibrosis is variable and highly dependent on the drug. For example $0.01 \%$ of patients receiving nitrofurantoin get pulmonary fibrosis while up to $40 \%$ of patients taking amiodarone develop pulmonary fibrosis (Camus et al., 2004). The pathogenesis of pulmonary fibrosis depends on the drug, is poorly understood and beyond the scope of this review. Histology may vary from CNSIP, FNSIP, UIP, and granulomatous changes, all of which can eventually lead to pulmonary fibrosis. The clinical presentation is usually marked by cough and dyspnea of varying degree and may be chronologically related to ingestion or administration of the drug (Camus et al., 2004). HRCT is not specific and may show ground glass, nodules, consolidation and fibrosis. The diagnosis is often made after excluding other causes of diffuse infiltrative lung disease, especially infection (Camus et al., 2004).

\section{Idiopathic Pulmonary Fibrosis}

Idiopathic pulmonary fibrosis (IPF), known as cryptogenic fibrosing alveolitis (CFA) in Europe, is a chronic fibrosing interstitial pneumonia with no known etiology (American Thoracic Society, 2001; Nemery et al., 2001; Khalil et al., 2005). The pathogenesis of fibrosis is very complex but one speculation is that aberrancy in the alveolar epithelial cell production of cytokines that can lead to parenchymal lung remodeling (Khalil et al., 1996, 1999, 2001, 2003; Khalil and O'Connor, 2004; Figure 6A). IPF is confined to the lungs and on surgical biopsy has a very characteristic histological pattern of temporal heterogeneity with normal lung interspersed with interstitial fibrosis and fibroblast foci (American Thoracic Society, 2001; Green, 2002; Camus et al., 2004).

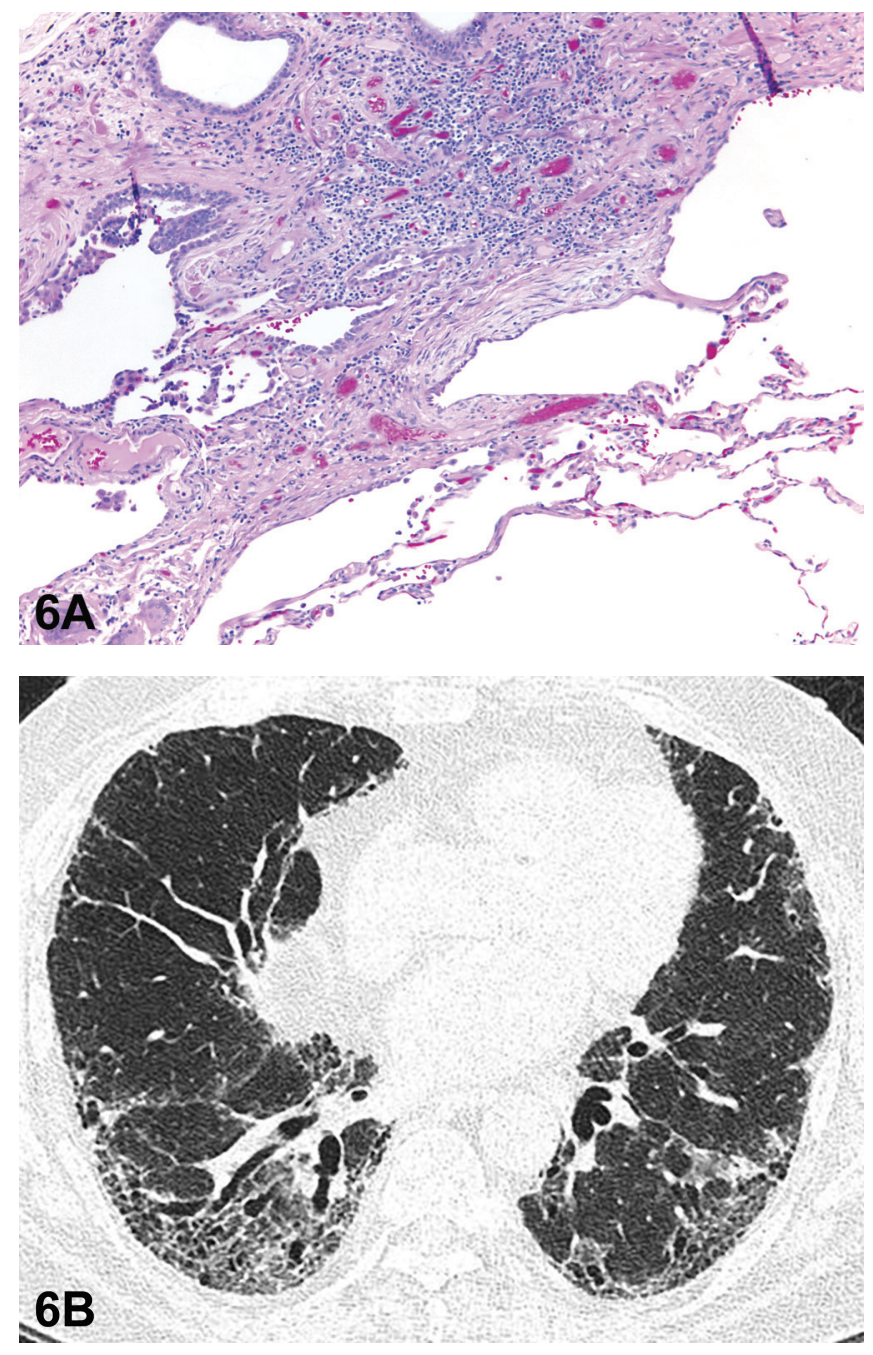

FIGURE 6.-Idiopathic pulmonary fibrosis. (A) Histology of usual interstitial pneumonitis. There are fibroblast foci (short arrow), dense interstitial fibrosis (long arrow), and normal lung $\left(^{*}\right)$. (B) HRCT shows subpleural fibrosis, honeycomb cysts, and traction bronchiectasis.

Patients with IPF present with insidious and progressive cough and dypnoea. HRCT shows interstitial fibrosis, traction bronchiectasis, and honeycomb cysts compatible with parenchymal lung remodeling. The etiology of IPF is unknown but some risk factors have been identified to be associated with IPF such cigarette smoking, farming, hairdressing, stone cutting, exposure to livestock, metal dust, birds, vegetables and animal dust (Nemery et al., 2001).

\section{INVESTIGATIONS OF PULMONARY FIBROSIS}

Lung function studies are not specific for any of these disorders and in general demonstrate a restrictive pattern with decreased volumes and capacities, abnormal gas exchange reflected in decrease in gas transfer and sometimes desaturation with exertion. In some instances there is evidence of airway obstruction reflecting inflammatory or fibrotic changes in the airways. Disorders with a combination of restrictive and obstructive pattern from the diseases are HP, beryllosis and hard metal lung disease (De Vuyst and Camus, 2000; American Thoracic Society, 2001; Nemery et al., 2001; Glazer et al., 
2002; Green, 2002; Jacobs et al., 2002; Kim and Lynch, 2002; Luster, 2002; Glazer and Newman, 2004; Ross and Murray, 2004; Jacobs et al., 2005).

Arterial blood gases can show hypoxemia, hypocapnia, and respiratory alkalosis (Yi, 2002). These changes may revert if there have been no permanent alterations (Yi, 2002). Up to $20-40 \%$ of patient with HP have reactive airways and up to 5-10\% of patients with HP may develop asthma (Yi, 2002). Blood tests are very nonspecific and not diagnostic. The erythrocyte sedimentation rate (ESR) may be elevated in some disorders where there is a systemic response such as in HP, berylliosis, and hard metal lung disease.

In berylliosis the T-lymphocyte proliferation test is suggestive of exposure and immune response. In hard-metal lung disease the serum can be used to quantify cobalt and confirm exposure (Nemery et al., 2001). Precipitating antibodies to thermophilic actinomycete or avian antigens identify exposure to these antigens but are not necessarily diagnostic of HP and in many patients with HP the precipitating antibodies may be negative.

There is no effective treatment for the pneumoconioses, berylliosis, drug-induced pulmonary fibrosis or hard-metal lung disease. Prevention and removal from the source of the inciting agent are the best therapeutic options and some patients respond favorably to corticosteroids.

In summary, many exogenous agents can cause pulmonary fibrosis. Adequate evaluation, diagnosis and treatment of pulmonary fibrosis require knowledge of the potential causes and a very thorough clinical history. HRCT is helpful in suggesting a diagnosis, and a diagnostic lung biopsy may reveal one of many well-described histological changes. Prevention of exposure is the best therapeutic options but corticosteroids may be beneficial in same cases.

\section{REFERENCES}

Aberer, W., Woltsche, M., Woltsche-Kahr, I., and Kranke, B. (2001). IgG antibodies typical for extrinsic allergic alveolitis—an inter-laboratory quality assessment. Eur J Med Res 20, 498-504.

American Thoracic Society/European Respiratory Society International Multidisciplinary Consensus Classification of the Idiopathic Interstitial Pneumonias (2002). This joint statement of the American Thoracic Society (ATS), and the European Respiratory Society (ERS) was adopted by the ATS board of directors, 2001 and by the ERS Executive Committee, June 2001. Am J Respir Crit Care Med 165, 277-304.

Ando, M., Suga, M., and Kohrogi, H. (1999). A new look at hypersensitivity pneumonitis. Curr Opin Pulm Med 5, 299-304.

Arakawa, H., Honma, K., Saito, Y., Shida, H., Morikubo, H., Suganuma, N., and Fujioka, M. (2005). Pleural disease in silicosis: pleural thickening, effusion, and investigation. Radiology 236, 685-93.

Attfield, M. D., and Wood, J. M. (2004). Changing patterns of pneumoconiosis mortality-United States, 1968-2000. Mortality and Morbidity Weekly Report, 53, 626-32.

Baur, X., Richter, G., Pethran, A., Czuppon, A. B., and Schwaiblmair, M. (1992). Increased prevalence of IgG-induced sensitization and hypersensitivity pneumonitis (humidifier lung) in nonsmokers exposed to aerosols of a contaminated air conditioner. Respiration 59, 211-4.

Camarena, A., Juarez, A., Mejia, M., Estrada, A., Carrillo, G., Falfan, R., Zuniga, J., Navarro, C., Granados, J., and Selman, M. (2001). Major histocompatibility complex and tumor necrosis factor-alpha polymorphisms in pigeon breeder's disease. Amer J Respir Crit Care Med 163, 1528-33.

Camus, P., Bonniaud, P., Fanton, A., Camus, C., Baudaun, N., and Foucher, P. (2004). Drug-induced and iatrogenic infiltrative lung disease. Clin Chest Med 25, 479-519.
Camus, P., Fanton, A., Bonniaud, P., Camus, C., and Foucher, P. (2004). Interstitial lung disease induced by drugs and radiation. Respiration 71, 301-26.

Camus, P., Kudoh, S., and Ebina, M. (2004). Interstitial lung disease associated with drug therapy. Br J Cancer 91 (Suppl 2), S18-23.

Chen, B., Tong, Z., Nakamura, S., Costabel, U., and Guzman, J. (2004). Production of IL-12, IL-18 and TNF-alpha by alveolar macrophages in hypersensitivity pneumonitis. Sarcoidosis Vasc Diffuse Lung Dis 21,199-203.

Chen, B., Tong, Z., Ye, Q., Nakamura, S., Costabel, U., and Guzman. J. (2005). Expression of tumour necrosis factor receptors by bronchoalveolar cells in hypersensitivity pneumonitis. Eur Respir J 25, 1039-43.

Chong, S., Lee, K. S., Chung, M. J., Han, J., Kwon, O. J., and Kim, T. S. (2006). Pneumoconiosis: comparison of imaging and pathologic findings. Radiographics 26, 59-77.

Churg, A., Muller, N. L., Flint, J., and Wright, J. L. (2006). Chronic hypersensitivity pneumonitis. Amer J Surg Pathol 30, 201-8.

Coultas, D. B., Zumwalt, R. E., Black, W. C., and Sobonya, R. E. (1994). The epidemiology of interstitial lung diseases. Am J Respir Crit Care Med 150, 967-72.

Da Broi, U., Orefice, U., Cahalin, C., Bonfreschi, V., and Cason, L. (1999). ARDS after double extrinsic exposure hypersensitivity pneumonitis. Intensive Care Med 25, 755-7.

Davies, G., Wells, A. U., and du Bois, R. M. (2004). Respiratory bronchiolitis associated with interstitial lung disease and desquamative interstitial pneumonia. Clin Chest Med 25, 717-26.

De Vuyst, P., and Camus, P. (2000). The past and present of pneumoconioses. Curr Opin Pulm Med 6, 151-6.

Ding, M., Chen, F., Shi, X., Yucesoy, B., Mossman, B., and Vallyathan, V. (2002). Diseases caused by silica: mechanisms of injury and disease development. Int Immunopharmacol 2-3, 173-82.

Flynn, M. R., and Susi, P. (2003). Engineering controls for selected silica and dust exposures in the construction industry-a review. Appl Occup Environ Hyg 18, 268-77.

Girard, M., Israel-Assayag, E., and Cormier, Y. (2004). Pathogenesis of hypersensitivity pneumonitis. Curr Opin Allergy Clin Immunol 4, 93-8.

Glazer, C. S., and Newman L. S. (2004). Occupational interstitial lung disease. Clin Chest Med 25, 467-78.

Glazer, C. S., Rose, C. S., Lynch, D. A. (2002). Clinical and radiologic manifestations of hypersensitivity pneumonitis. J Thorac Imag 17, 261-72.

Green, F. H. (2002). Overview of pulmonary fibrosis. Chest $\mathbf{1 2 2}$ (6 Suppl), 334S339S. Am J Respir Crit Care Med 165, 277-304.

Gudmundsson, G., and Hunninghake, G. W. (1997). Interferon-gamma is necessary for the expression of hypersensitivity pneumonitis. J Clin Invest $\mathbf{9 9}$, 2386-90.

Herraez, I., Gutierrez, M., Alonso, N., and Allende, J. (2002). Hypersensitivity pneumonitis producing a BOOP-like reaction: $\mathrm{HRCT} /$ pathologic correlation. J Thorac Imag 17, 81-3.

Hodgson, M. J., Morey, P. R., Simon, J. S., Waters, T. D., and Fink, J. N. (1987). An outbreak of recurrent acute and chronic hypersensitivity pneumonitis in office lung with respect to age, sex, atopy, and smoking. Eur J Respir Dis Suppl 152, 19-28.

Jacobs, R. L., Andrews, C. P., and Coalson J. J. (2002).Organic antigen-induced interstitial lung disease: diagnosis and management. Ann Allergy Asthma Immunol 88, 30-41.

Jacobs, R. L., Andrews, C. P., and Coalson, J. J. (2005). Hypersensitivity pneumonitis: beyond classic occupational disease-changing concepts of diagnosis and management. Ann Allergy Asthma Immunol 95, 115-28.

Kalish, R. S., and Askenase, P. W. (1999).Molecular mechanisms of CD8+ T cell-mediated delayed hypersensitivity: implications for allergies, asthma, and autoimmunity. J Allergy Clin Immunol 103(2 Pt 1),192-9.

Kang, B. Y., and Kim, T. S. (2006). Targeting cytokines of the interleukin-12 family in autoimmunity. Curr Med Chem 13, 1149-56.

Katzenstein, A. L., and Fiorelli, R. F. (1994). Nonspecific interstitial pneumonia/fibrosis. Histologic features and clinical significance. Am J Surg Pathol 18, 136-47

Katzenstein, A. L., Zisman, D. A., Litzky, L. A., Nguyen, B. T., and Kotloff, R. M. (2002). Usual interstitial pneumonia: histologic study of biopsy and explant specimens. Amer J Surg Pathol 26, 1567-77. 
Khalil, N. and O'Connor, R. (2004). Idiopathic pulmonary fibrosis: current understanding of the pathogenesis and the status of treatment. Can Med Assoc $J$ 171, 153-60.

Khalil, N., O'Connor, R., Flanders, K., and Unruh, H. (1996). TGF-beta1 but not TGF-beta 2 or TGF-beta 3 are differentially present in epithelial cells of advanced pulmonary fibrosis: an immunohistochemical study. Am J Resp Cell Mol Biol 14, 131-8.

Khalil, N., O'Connor, R., Unruh, H., Warren, P., Kemp, A., Bereznay, O., Flanders, K., and Greenberg, A. H. (1991). Increased production and immunohistochemical localization of transforming growth factor-beta (TGFbeta) in idiopathic pulmonary fibrosis. Amer J Resp Cell Mol Biol 5, 15562.

Khalil, N., Trilok, P., O'Connor, R., Antman, N., Kepron, W., Yehaulaeshet, T., Xu, Y.-D., and Gold, L. (2001). The regulation of TGF- $\beta 1$ in idiopathic pulmonary fibrosis by the activation of latent TGF- $\beta 1$ and differential expression of TGF- $\beta$ receptors (T $\beta$ R-I and T $\beta$ R-II). Thorax 56, 907-15.

Khalil, N., Xu, Y. D., Duronio, V., and O'Connor, R. (2005). Proliferation of interstitial pulmonary fibroblasts is mediated by TGF- $\beta 1$ induced FGF- 2 phosphorylation of p38 MAPK and JNK .J Biol Chem 280, 43000-9.

Kim, J. S., and Lynch, D. A. (2002). Imaging of nonmalignant occupational lung disease. J Thorac Imag 17, 238-60.

Lacasse, Y., Selman, M., Costabel, U., Dalphin, J. C., Ando, M., Morell, F., Erkinjuntti-Pekkanen, R., Muller, N., Colby, T. V., Schuyler, M., Cormier, Y., and HP Study Group (2003). Clinical diagnosis of hypersensitivity pneumonitis.Am J Respir Crit Care Med 168, 952-8.

Lee, K. Y., Ito, K., Hayashi, R., Jazrawi, E. P., Barnes, P. J., and Adcock, I. M. (2006). NF-kappaB and activator protein 1 response elements and the role of histone modifications in IL-1beta-induced TGF-betal gene transcription. J Immunol 176, 603-15.

Lopez, M., and Salvaggio, J. E. (1987). Epidemiology of hypersensitivity pneumonitis/allergic alveolitis.Monogr Allergy 21, 70-86.

Luster, M. (2002). Preface to occupational immunology. Inter Immunopharm $\mathbf{2}$, $161-2$.

Manning, C. B, Vallyathan, V., and Mossman, B. T. (2002). Diseases caused by asbestos: mechanisms of injury and disease development. Int Immunopharmacol 2, 191-200.

Martinez, F. J. (2006). Idiopathic interstitial pneumonias: usual interstitial pneumonia versus nonspecific interstitial pneumonia. Proc Am Thorac Soc $\mathbf{3}$, $81-95$.

Mohr, L. C. (2004). Hypersensitivity pneumonitis. Curr Opin Pulm Med 10, 401-11.

Mongan, L. C., Jones, T., and Patrick, G. (2000). Cytokine and free radical responses of alveolar macrophages in vitro to asbestos fibers. Cytokine 12, 1243-7.

Morris, D. G. (2003). Gold, silver, and bronze: metals, medals, and standards in hypersensitivity pneumonitis. Am J Respir Crit Care Med 168(8), 909-10.

Navarro, C., Mejia, M., Gaxiola, M., Mendoza, F., Carrillo, G., and Selman, M. (2006). Hypersensitivity pneumonitis: a broader perspective. Treat Respir Med 5, 167-79.

Nemery, B., Bast, A., Behr, J., Borm, P. J., Bourke, S. J., Camus, P. H., De Vuyst, P., Jansen, H. M., Kinnula, V. L., Lison, D., Pelkonen, O., and Saltini, C. (2001). Interstitial lung disease induced by exogenous agents: factors governing susceptibility. Eur Respir J Suppl 32, 30s-42s.

Nemery, B., Verbeken, E. K., and Demedts, M. (2001). Giant cell interstitial pneumonia (hard metal lung disease, cobalt lung). Semin Respir Crit Care Med 22, 435-48.
NIH Research Findings (1978). Recent studies show workers exposed to asbestos years ago are greater risk for some diseases. JAMA 239, 2431-2.

Ohtani, Y., Saiki, S., Kitaichi, M., Usui, Y., Inase, N., Costabel, U., and Yoshizawa, Y. (2005). Chronic bird fancier's lung: histopathological and clinical correlation. An application of the 2002 ATS/ERS consensus classification of the idiopathic interstitial pneumonias. Thorax 60, 665-71.

Ohtani, Y., Saiki, S., Sumi, Y., Inase, N., Miyake, S., Costabel, U., and Yoshizawa, Y. (2003). Clinical features of recurrent and insidious chronic bird fancier's lung. Ann Allergy Asthma Immunol 90, 604-10.

Patel, A. M., Ryu, J. H., and Reed, C. E. (2001). Hypersensitivity pneumonitis: current concepts and future questions. J Aller Clin Immunol 108, 661-70.

Rimal, B., Greenberg, A. K., and Rom, W. N. (2005). Basic pathogenetic mechanisms in silicosis: current understanding. Curr Opin Pulm Med 11,169-73.

Ross, M. H., and Murray, J. (2004). Occupational respiratory disease in mining. Occup Med (Lond) 54, 304-10.

Ryu, J. H. (2006). Classification and approach to bronchiolar diseases. Curr Opin Pulm Med 12, 145-51.

Scabilloni, J. F., Wang, L., Antonini, J. M., Roberts, J. R., Castranova, V., and Mercer, R. R. (2005). Matrix metalloproteinase induction in fibrosis and fibrotic nodule formation due to silica inhalation. Amer J Physiol Lung Cell Mol Physiol 288, L709-17.

Schuyler, M. (2001). Are polymorphisms the answer in hypersensitivity pneumonitis? Amer J Respir Crit Care Med 163(7),1513-4.

Selman, M. (2004). Hypersensitivity pneumonitis: a multifaceted deceiving disorder. Clin Chest Med 25, 531-47.

Stauffer Ettlin, M., Pache, J. C., Renevey, F., Hanquinet-Ginter, S., Guinand, S., and Barazzone Argiroffo, C. (2006). Bird breeder's disease: a rare diagnosis in young children. Eur J Pediatr 165, 55-61.

Swigris, J. J., Berry, G. J., Raffin, T. A., and Kuschner, W. G. (2002). Lymphoid interstitial pneumonia: a narrative review. Chest 122, 2150-64.

Tefferi, A., Patnaik, M., and Pardanani, A. (2006). Eosinophilia: secondary, clonal and idiopathic. Brit J Haematol 133, 468-92.

Terho, E. O., Husman, K., and Vohlonen. I. (1987). Prevalence and incidence of chronic bronchitis and farmer's lung with respect to age, sex, atopy, and smoking. Eur J Respir Dis Suppl. 152,19-28.

Thomeer, M. J., Costabe, U., Rizzato, G., Poletti, V., and Demedts, M. (2001). Comparison of registries of interstitial lung diseases in three European countries. Eur Respir J Suppl 32,114s-118s.

Vanhee, D., Gosset, P., Boitelle, A., Wallaert, B., and Tonnel, A. B. (1995). Cytokines and cytokine network in silicosis and coal workers' pneumoconiosis. Eur Respir J 8, 834-42.

Wallis, R. S., and Ehlers, S. (2005). Tumor necrosis factor and granuloma biology: explaining the differential infection risk of etanercept and infliximab. Semin Arthritis Rheum 34(5 Suppl1), 34-8.

Wild, L. G., and Lopez, M. J. (2001). Hypersensitivity pneumonitis: a comprehensive review. Investig Allergol Clin Immunol 11, 3-15.

Xu, Y. D., Hua, J., Mui, A., O'Connor, R., Grotendorst, N., and Khalil, N. (2003). Release of biologically active TGF-betal by alveolar epithelial cells results in pulmonary fibrosis. Am J Physiol: Lung Cell Mol Physiol 285, L527-39.

Yi, E. S. (2002). Hypersensitivity pneumonitis. Crit Rev Clin Lab Sci 39, 581629.

Zacharisen, M. C., Schlueter, D. P., Kurup, V. P., and Fink, J. N. (2002). The longterm outcome in acute, subacute, and chronic forms of pigeon breeder's disease hypersensitivity pneumonitis. Ann Allergy Asthma Immunol $\mathbf{8 8}$, $175-82$. 